\title{
Erratum to: Clinical associations between IL-17 family cytokines and periodontitis and potential differential roles for IL-17A and IL-17E in periodontal immunity
}

Raja Azman Awang - David F. Lappin - Alexandrea MacPherson •

Marcello Riggio • Douglas Robertson • Penny Hodge • Gordon Ramage •

Shauna Culshaw $\cdot$ Philip M. Preshaw $\cdot$ John Taylor $\cdot$ Christopher Nile

Published online: 12 December 2014

(C) Springer Basel 2014

Erratum to: Inflamm. Res. (2014) 63:1001-1012

DOI 10.1007/s00011-014-0776-7

In the original publication, the first author's name was incorrectly published as Raja Azman. The correct name should read as Raja Azman Awang.

The online version of the original article can be found under doi:10.1007/s00011-014-0776-7.

R. A. Awang - D. F. Lappin - A. MacPherson · M. Riggio ·

D. Robertson · P. Hodge · G. Ramage - S. Culshaw ·

C. Nile $(\square)$

Infection and Immunity Research Group, Immunology, Level 9,

Dental School, School of Medicine, College of Medical,

Veterinary and Life Sciences, University of Glasgow, 378

Sauchiehall Street, Glasgow G2 3JZ, UK

e-mail: christopher.nile@glasgow.ac.uk

P. M. Preshaw $\cdot$ J. Taylor

Centre for Oral Health Research and Institute of Cellular

Medicine, Framlington Place, Newcastle University, Newcastle

upon Tyne NE2 4BW, England, UK 